\title{
Incorporation of Vanadium Oxide in Silica Nanofiber Mats via Electrospinning and Sol-Gel Synthesis
}

\author{
Jeanne E. Panels and Yong Lak Joo \\ School of Chemical and Biomolecular Engineering, Cornell University, Ithaca, NY 14853, USA
}

Received 4 April 2006; Revised 8 September 2006; Accepted 19 September 2006

\begin{abstract}
Submicron scale vanadia/silica hybrid nanofiber mats have been produced by electrospinning silica sol-gel precursor containing vanadium oxytriisopropoxide (VOTIP), followed by calcinations at high temperature. The properties of the resulting inorganic hybrid nanofiber mats are compared to those of electrospun pure silica nanofibers. SEM images show fibers are submicron in diameter and their morphology is maintained after calcination. Physisorption experiments reveal that silica nanofiber mats have a high specific surface area of $63 \mathrm{~m}^{2} / g$. FT-IR spectra exhibit $\mathrm{Si}-\mathrm{O}$ vibrations and indicate the presence of $\mathrm{V}_{2} \mathrm{O}_{5}$ in the fibers. XPS studies reveal that the ratio of $\mathrm{Si}$ to $\mathrm{O}$ is close to 0.5 on the surface of fibers and the amount of vanadium on the surface of fibers increases with calcination. XRD diffraction patterns show that silica nanofibers are amorphous and orthorhombic $\mathrm{V}_{2} \mathrm{O}_{5} \mathrm{crystals}$ have formed after calcination. EFTEM images demonstrate the growth of crystals on the surface of fibers containing vanadium after calcination. SEM images of fibers with high-vanadium content $(50 \mathrm{~mol} \% \mathrm{~V}: \mathrm{Si}$ ) show that vanadia crystals are mostly aligned along the fiber axis. XPS shows an increase in vanadium contents at the surface, and XRD patterns exhibit an increase in the degree of crystallinity. A coaxial electrospinning scheme has successfully been employed to selectively place $\mathrm{V}_{2} \mathrm{O}_{5}$ in the skin layer.
\end{abstract}

Copyright ( $) 2006$ J. E. Panels and Y. L. Joo. This is an open access article distributed under the Creative Commons Attribution License, which permits unrestricted use, distribution, and reproduction in any medium, provided the original work is properly cited.

\section{INTRODUCTION}

Electrospinning is a fiber formation process typically used to produce nonwoven polymer fiber mats with diameters one or two orders of magnitude smaller than conventional textile fibers. Electrospinning produces mats with large surface area to mass ratios, typical surface areas can be $10 \mathrm{~m}^{2} / \mathrm{g}$ for fiber diameters of $500 \mathrm{~nm}$ and $1000 \mathrm{~m}^{2} / \mathrm{g}$ for diameters around $50 \mathrm{~nm}$ [1]. During electrospinning a strong electric field is used to draw a solution from the tip of a capillary to the collector. The electrostatic field causes a pendant droplet of the solution at the capillary tip to deform into a conical shape or a Taylor cone. When the electrical force at the surface of the solution overcomes the surface tension a fine, charged jet is ejected. The jet moves toward a ground plate acting as a counter electrode. The solvent begins to evaporate immediately after the jet is formed causing the deposit of a thin fiber on the collector plate [1]. We refer the reader to recent reviews that elaborate on the versatility and promise of electrospinning processes [1-3].

One dimensional, inorganic, nanosized fibers and fibrous mats are of interest for their high thermal stability and large surface to mass ratios. Recently, silica nanofiber mats have been produced using a sol-gel synthesis/electrospinning technique without using any polymer binder [4]. Silica nanofiber mats provide an ideal platform for the incorporation of transition metals and their oxide particles [5]. Previously, the incorporation of metal oxides into electrospun fibers has been achieved using polymer as a binder or a matrix due to its better processabilities. However, calcination at high temperature is needed to grow transition metal oxide crystals and high temperature treatment in turn weakens fibers due to the disintegration of the polymer matrix in fibers [6]. If silica is used as a matrix, however, metal precursors can be included by directly adding them to the sol-gel precursor [7], and the growth of crystalline metal oxides on silica fibers can be achieved, while the fiber morphology is preserved during calcination.

In the present study, we incorporate $\mathrm{V}_{2} \mathrm{O}_{5}$ into silica nanofibers, and the effect of the inclusion of $\mathrm{V}_{2} \mathrm{O}_{5}$ on the properties of silica nanofibers is investigated. More specifically, we developed submicron scale vanadia/silica hybrid fiber mats by electrospinning a silica sol-gel precursor containing vanadium oxytriisopropoxide (VOTIP), followed by calcinations at high temperatures. Resulting silica nanofibers containing vanadium pentoxide crystal particles can be used 
to detect trace amounts of toxic or flammable gases such as ammonia and hydrocarbons. If vanadium oxide comes into contact with trace amounts of toxic or flammable gases the surface conductance changes, indicating the presence of small amounts of gases [6]. It is important to note that the sensitivity in sensing depends on grain size and smaller grain sizes lead to an increase in the sensitivity [8]. We anticipate that this simple and versatile electrospinning/sol-gel directed approach to conducting layers that combine a large surface area as well as electrical interactions will lead to more sensitive detection in sensing gases. Dispersing $\mathrm{V}_{2} \mathrm{O}_{5}$ nanoparticles onto the surface of silica nanofibers may allow outstanding specificity and selectivity in gas sensing to be gained. Currently, thin films containing $\mathrm{V}_{2} \mathrm{O}_{5}$ are used for sensing toxic or flammable gases, but this method only utilizes the limited surface layer of the film because the gas flows over the film $[9,10]$. Nanofiber mats can provide a highly porous network which the gas can flow through, and thus the entire active sites on fibers are effectively utilized.

Coaxial electrospinning is a technique that uses a dual syringe system during electrospinning [11]. It allows the creation of hollow nanofibers, with the outer syringe containing an inorganic substance and the inner syringe containing an organic substance, such as mineral oil. Fibers can then be calcined at the appropriate temperature to eliminate organics inside the fiber, while the inorganic part of the fiber will remain and therefore create a hollow, tubular nanostructure. Using a coaxial spinning scheme, hollow silica fibers containing $\mathrm{V}_{2} \mathrm{O}_{5}$ particles have been produced. Coaxial electrospinning can provide a useful means to produce vanadia-silica nanofiber mats for gas sensing, because $\mathrm{V}_{2} \mathrm{O}_{5}$ crystals can be placed selectively in the skin layer of fibers such that the loading of transition metal oxides can be greatly reduced.

\section{EXPERIMENTAL PROCEDURE}

Tetra(ethyl) ortho silicate (TEOS) and VOTIP were supplied by Aldrich. To produce silica nanofibers, a solution that undergoes a sol-gel synthesis reaction was prepared with the molar ratio of TEOS : EtOH : $\mathrm{H}_{2} \mathrm{O}: \mathrm{HCl}$ being $1: 2: 2$ : 0.01 . After vigorous mixing to produce a homogeneous solution, the solution was placed in a $50^{\circ} \mathrm{C}$ oven to accelerate the sol-gel transition. When vanadia/silica fibers were desired, a VOTIP/EtOH solution containing half of the overall EtOH contents was added after vigorous mixing of the TEOS/EtOH and $\mathrm{H}_{2} \mathrm{O} / \mathrm{HCl}$ solutions. The spinning solution contained a $23 \mathrm{~mol} \% \mathrm{~V}$ : Si ratio, while a $50 \mathrm{~mol} \% \mathrm{~V}$ : Si ratio was also used to obtain a higher vanadium content in silica fibers. After ripening for $3-5 \mathrm{~h}$, the solution was electrospun with an applied voltage of $20 \mathrm{kV}$, a flow rate of $0.03 \mathrm{~mL} / \mathrm{min}$, and a tip to collector distance of 4.5 inches. These spinning conditions were carefully chosen to obtain a continuous production of submicron scale fibers. A sample of electrospun fibers was then heated to $150^{\circ} \mathrm{C}$ for $1 \mathrm{~h}$ to remove residual solvents followed by calcination at $600 \sim 800^{\circ} \mathrm{C}$ in a tube furnace heated at a rate of $5^{\circ} \mathrm{C} / \mathrm{min}$ for $1 \sim 6 \mathrm{~h}$.

A $23 \mathrm{~mol} \% \mathrm{~V}$ : Si sol-gel precursor containing TEOS and VOTIP was prepared in the same manner as mentioned previously for coaxial electrospinning. The coaxial electrospin-

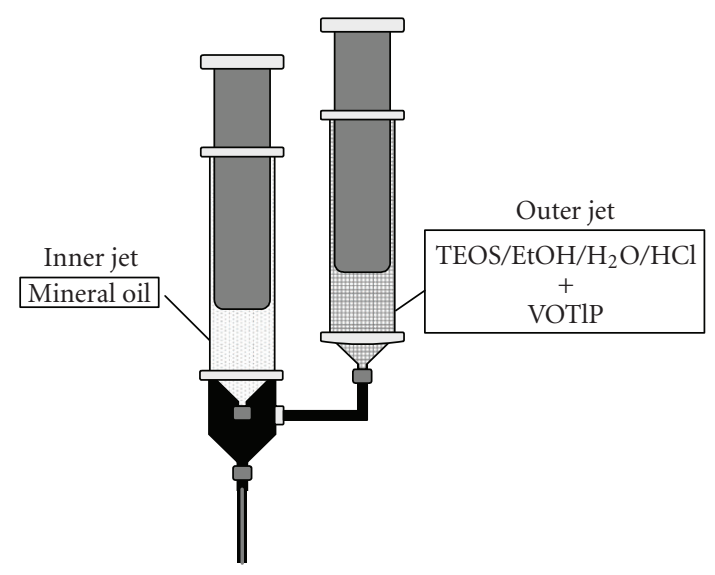

Figure 1: Coaxial electrospinning set-up.

ning set up used in the current study is shown in Figure 1. The sol-gel solution was used for the outer syringe with an inner nozzle diameter of $0.84 \mathrm{~mm}$ and mineral oil was used for the inner syringe with an inner nozzle diameter of $0.15 \mathrm{~mm}$. The mineral oil had a constant flow rate of $0.01 \mathrm{~mL} / \mathrm{min}$, while the flow rate of the TEOS/VOTIP solution was controlled by gravity. The applied voltage was $20 \mathrm{kV}$ and the tip-to-collector distance was 4.5 inches. The collected fibers were heated to $150^{\circ} \mathrm{C}$ for $1 \mathrm{~h}$ to remove residual solvents. The coaxially spun fibers were heated at a rate of $5^{\circ} \mathrm{C} / \mathrm{min}$ and calcined at $1000^{\circ} \mathrm{C}$ for $6 \mathrm{~h}$ to grow vanadium oxide crystals and remove the mineral oil to create hollow fibers.

Scanning electron microscopy (SEM) was conducted using the LEICA 440 and the samples were coated using an AuPd sputterer. Specific surface area and pore size distribution of electrospun fiber mats were measured using a micrometrics physi/chemi sorption analyzer and gases used for measurements were either $\mathrm{N}_{2}$ or $\mathrm{Kr}$. X-ray diffraction (XRD) was done on the Scintag, Inc. Theta-Theta Diffractometer, using a Cu target and a step size of $0.02^{\circ}$. Energy filtering transmission electron microscopy (EFTEM) was conducted using the FEI Tecnai G20. Thermogravimetric analysis (TGA), Fourier transform infrared spectroscopy (FT-IR), and X-ray photoelectron spectroscopy (XPS) experiments were also conducted to characterize electrospun silica-vanadia fibers before and after calcination.

\section{RESULTS AND DISCUSSION}

\subsection{Effect of Inclusion of VOTIP on the properties of sol-gel precursor}

Since the conductivity and viscosity of the solution affects both initial thinning behavior and whipping motion of the jet during electrospinning, one can easily surmise that the final fiber diameter can be influenced by the inclusion of vanadium oxide precursor in the silica-sol precursor. The effect of inclusion of vanadium particles on both conductivity and viscosity of the sol-gel precursor is presented in this section. 


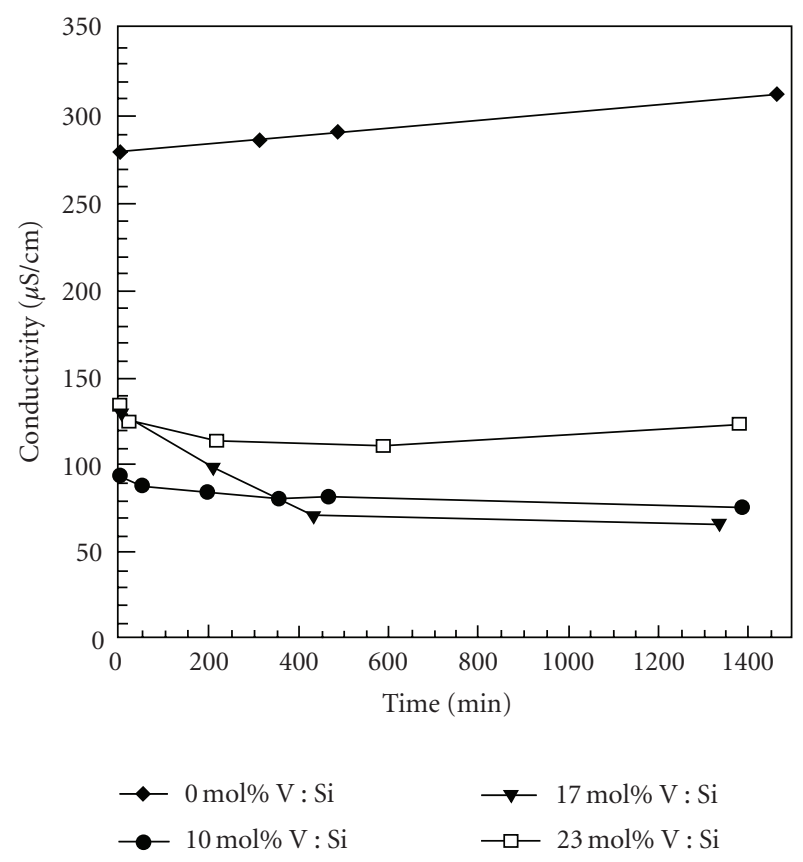

FIGURE 2: Evolution of conductivity of electrospinning solutions containing various amounts of vanadium.

First, conductivity measurements were carried out using a digital conductivity meter (VWR scientific products). The solutions used for conductivity measurements had the same composition as solutions used in electrospinning experiments and they contained various amounts of VOTIP ranging from $0 \sim 23 \mathrm{~mol} \% \mathrm{~V}$ to Si ratio. The change in conductivity during the sol-gel transition was measured over time. Figure 2 indicates that the presence of vanadium particles in the sol-gel solution substantially decreases its conductivity from $300 \mu \mathrm{S} / \mathrm{cm}$ to $100 \mu \mathrm{S} / \mathrm{cm}$. Since the conductivity of VOTIP solution is very low $(\sim 0.001 \mu \mathrm{S} / \mathrm{cm})$, the addition of VOTIP to the silica precursor resulted in a decrease in conductivity. However, there is no simple trend observed between the conductivity and the amount of vanadium in the solution. We note that a decrease in the solution conductivity, in general, leads to larger fiber diameters [12]. SEM images confirm that the vanadia/silica fibers have a larger average diameter than pure silica fibers under similar spinning conditions possibly due to the change in conductivity and viscosity.

Viscosity measurements of sol-gel precursor solutions containing various concentrations of vanadium have also been carried out on electrospinning solutions during the solgel transition. As shown in Figure 3, it is observed that the rate of gelation increases with increasing vanadium concentration. This suggests that as the vanadium concentration increases, solutions will be spinnable at an earlier time and the time period in which they remain spinnable will be shorter. It should be noted that for conventional spinning, silica precursors are spinnable in the range of 10-1000 Poise [7], while silica nanofibers were able to be obtained even at a lower initial solution viscosity ( 0.5 to 10 Poise) possibly due to the

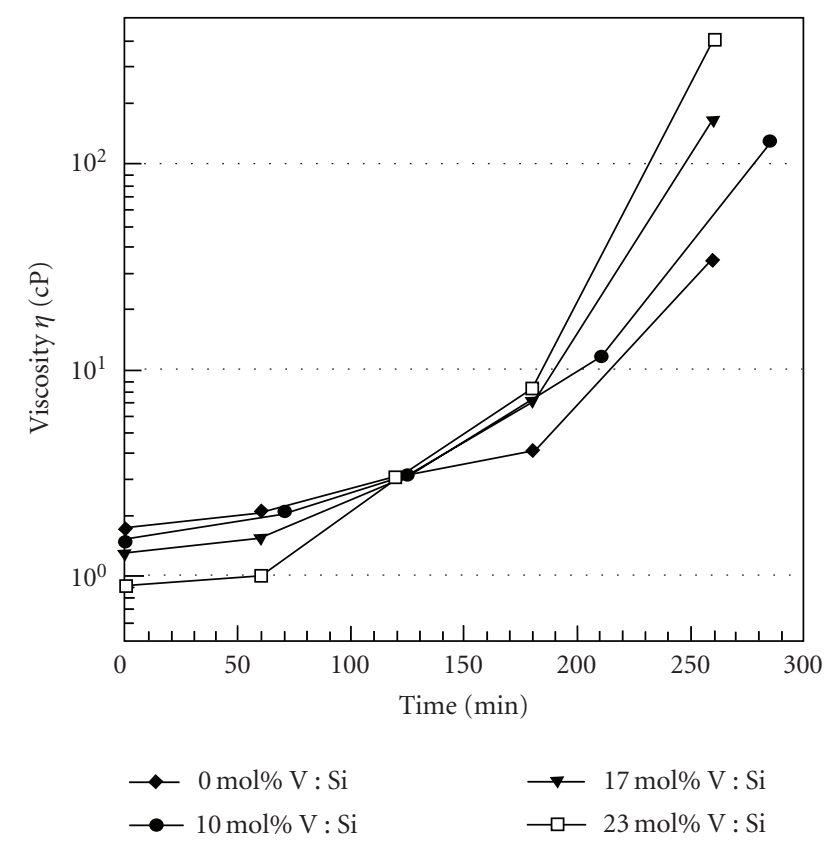

FIGURE 3: Evolution of viscosity of electrospinning solutions with various concentrations of vanadium.

faster evaporation of solvent and thus rapid sol-gel transition during electrospinning.

\subsection{Fiber morphology of electrospun nanofibers}

Silica sol-gel precursors with and without VOTIP were electrospun and the morphology of the electrospun fibers are presented in this section. First, the SEM images of silica fibers before and after calcination are shown in Figures 4(a) and 4(b), respectively. It is observed that pure silica fibers are submicron in diameter and they exhibit a relatively uniform size distribution. For an inner needle diameter of $0.18 \mathrm{~mm}$, asspun fibers and fibers after calcination range mostly from 100 to $400 \mathrm{~nm}$. As shown in Table 1, the average diameter of silica fibers before and after calcination is $270 \pm 100 \mathrm{~nm}$ and $260 \pm 70 \mathrm{~nm}$, respectively. It should be noted that even after heating at $600^{\circ} \mathrm{C}$ for $2 \mathrm{~h}$, the morphology of fibers is preserved. However, fibers after calcinations at $600^{\circ} \mathrm{C}$ for $2 \mathrm{~h}$ appear to exhibit a slightly rougher surface, which is most likely due to the evaporation of solvents and water upon heating.

The SEM images of electrospun silica fibers containing $23 \mathrm{~mol} \% \mathrm{~V}$ : Si before and after calcination are shown in Figures $4(\mathrm{c})$ and $4(\mathrm{~d})$. The image after calcination again shows slightly rougher fiber surfaces. In addition, calcined fibers clearly show some crystal growth on the fiber surface. As listed in Table 1, the average diameter of silica fibers containing vanadium is $510 \pm 220 \mathrm{~nm}$ after calcination at $800^{\circ} \mathrm{C}$, when using a nozzle with an inner diameter of $0.29 \mathrm{~mm}$, while the average diameter before calcination is $540 \pm 230 \mathrm{~nm}$. Although it appears that the average diameter decreases after calcination, the very large standard deviations put the average diameters within the range of one another. Table 1 


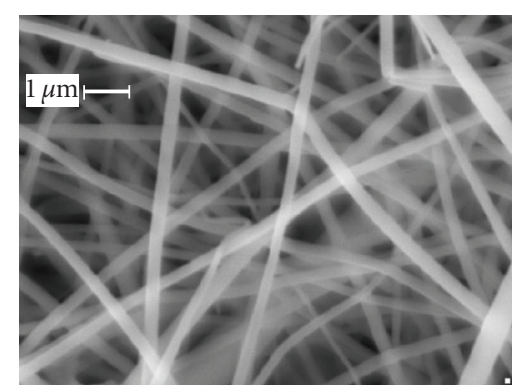

(a)

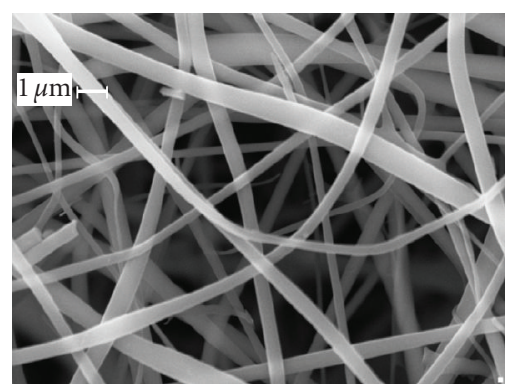

(c)

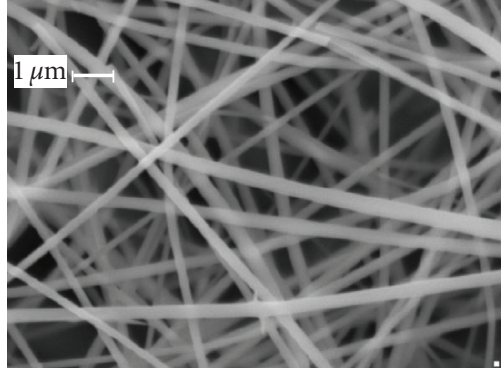

(b)

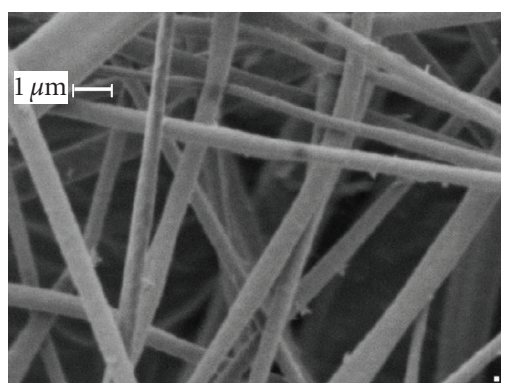

(d)

FIGURE 4: SEM images of (a) as-spun silica fibers (b) silica fibers after calcination at $600^{\circ} \mathrm{C}$ for $2 \mathrm{~h}$ (c) as-spun $23 \mathrm{~mol} \% \mathrm{~V}: \mathrm{Si}$ fibers (d) $23 \mathrm{~mol} \% \mathrm{~V}$ : Si fibers after calcination at $800^{\circ} \mathrm{C}$ for $6 \mathrm{~h}$. The inner diameter of the needle used during electrospinning was $0.29 \mathrm{~mm}$.

TABLE 1: Average diameters of pure silica and vanadia-silica fibers at various nozzle sizes.

\begin{tabular}{ccccc}
\hline Needle size (ID) & Silica fiber, as-spun & Silica fiber, $800^{\circ} \mathrm{C}$ & $23 \mathrm{~mol} \% \mathrm{~V}:$ Si fiber, as-spun & $23 \mathrm{~mol} \% \mathrm{~V}:$ Si fiber, $800^{\circ} \mathrm{C}$ \\
\hline $0.18 \mathrm{~mm}$ & $270 \pm 100$ & $260 \pm 70$ & - & - \\
$0.29 \mathrm{~mm}$ & $400 \pm 200$ & $370 \pm 160$ & $540 \pm 230$ & $510 \pm 220$ \\
$0.58 \mathrm{~mm}$ & - & - & $800 \pm 420$ & $770 \pm 430$ \\
\hline
\end{tabular}

demonstrates that as the inner diameter of the nozzle decreases, the diameter of fibers also decreases. In addition, larger nozzle sizes lead to an increased variation in fiber diameters. Table 1 also shows that the addition of vanadium increases fiber diameter when compared with pure silica fibers. This may be due to the effect that the inclusion of VOTIP has on the conductivity and viscosity of the sol-gel precursor, as discussed in the previous section.

\subsection{Thermal and physical properties of electrospun nanofibers}

Thermogravimetric analysis (TGA) was applied to asspun fibers with and without VOTIP. The TGA curve in Figure 5(a) shows a weight loss of about $10 \mathrm{wt} \%$ at $200^{\circ} \mathrm{C}$ in electrospun silica fibers due to evaporation of residual solvents, while at $800^{\circ} \mathrm{C}$ the weight loss is about $17 \mathrm{wt} \%$. The extra weight loss at high temperature is a result of the self-condensation reactions of the silanol groups [4]. This result is in agreement with the FT-IR study (Figure 7) which indicates that intra- and inter-molecular hydrogen bonds of the silanol groups disappear after calcination at $800^{\circ} \mathrm{C}$. The TGA peak shown in Figure 5(b) was obtained for a silica fiber containing $23 \mathrm{~mol} \% \mathrm{~V}$ : Si up to $1200^{\circ} \mathrm{C}$ to verify the removal of residual solvents and the completion of self-condensation of silanol groups in fibers. The first steep decrease in weight loss up to $400^{\circ} \mathrm{C}$ shows the removal of residual solvents. A small weight loss continues to $900^{\circ} \mathrm{C}$, which points to a change in the composition of fibers. This most likely indicates the completion of self-condensation of silanol group as well as the formation and sublimation of $\mathrm{V}_{2} \mathrm{O}_{5}$ in the fibers at high temperature.

Physisorption analysis was carried out on pure silica fibers before and after calcination to obtain the BET surface area and information on pore size. The average diameter of electrospun silica fibers before calcination was $520 \pm$ $220 \mathrm{~nm}$. The BET surface area of as-spun fibers was reported as $15.6 \mathrm{~m}^{2} / \mathrm{g}$. After calcination at $600^{\circ} \mathrm{C}$ for $2 \mathrm{~h}$ the BET surface area increased to $65.3 \mathrm{~m}^{2} / \mathrm{g}$. The pore area distribution of electrospun silica nanofibers before and after calcination is also shown in Figure 6. It is observed that the pore area for small internal pores $(1 \mathrm{~nm} \sim 10 \mathrm{~nm})$ is increased, while that 


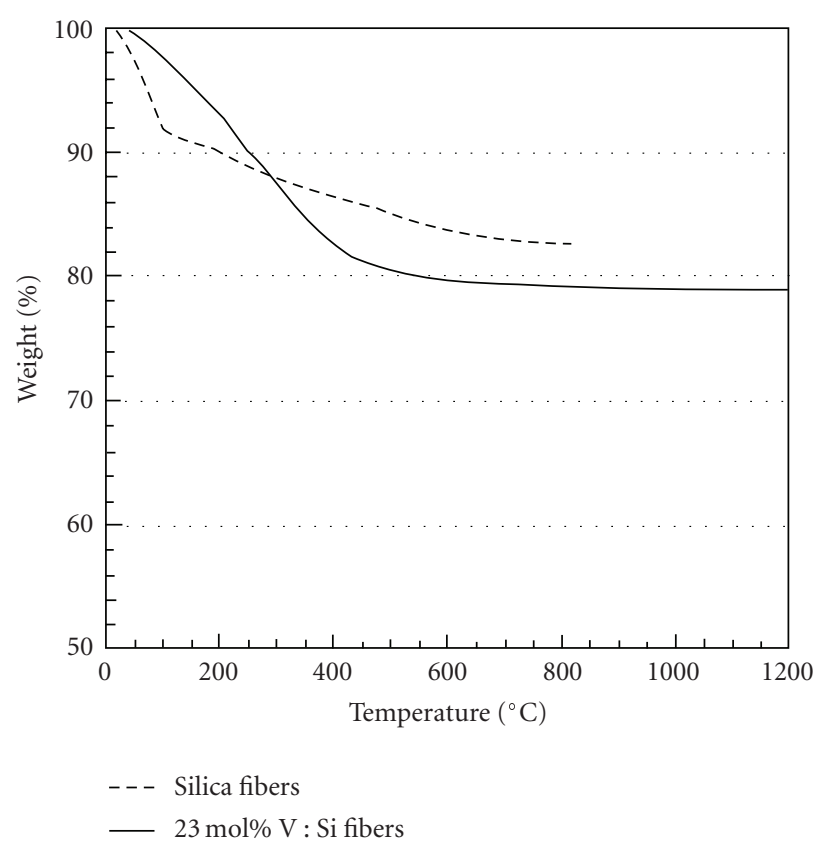

FIgURE 5: TGA curve of pure silica fibers and $23 \mathrm{~mol} \% \mathrm{~V}$ : Si fibers.

of large pores $(10 \mathrm{~nm} \sim 100 \mathrm{~nm})$ is decreased after calcination at $600^{\circ} \mathrm{C}$ for $2 \mathrm{~h}$. Hence, the observed increase in surface area is most likely due to the creation of small pores caused by the removal of residual solvents that occurs during calcination.

Physisorption analysis was also carried out on vanadia/silica fibers after calcination at $800^{\circ} \mathrm{C}$ for $6 \mathrm{~h}$. The BET surface area of the fibers after calcination was $1.9 \mathrm{~m}^{2} / \mathrm{g}$. This value is comparable to that for nanoparticles obtained from high-energy milling $\left(1 \sim 10 \mathrm{~m}^{2} / \mathrm{g}\right)$, but is much lower than those for nanoparticles obtained by gas phase condensation $\left(100 \mathrm{~m}^{2} / \mathrm{g}\right)[8]$. We note that the surface area of vanadia/silica fibers is much lower than that of silica fibers possibly due to the higher calcination temperature and larger deviation in vanadia/silica fiber diameter. As shown in Figure 6, not only the area of small pores but also the area of large pores in the vanadia/silica fibers calcined at $800^{\circ} \mathrm{C}$ are considerably lower than those of as-spun silica fibers and silica fibers calcined at $600^{\circ} \mathrm{C}$.

To identify the specific molecular components and structures in the electrospun silica fibers before and after calcination, FT-IR spectroscopy was carried out. Figure 7(a) shows that the FT-IR spectrum of the as-spun silica fibers has peaks at 1038,918 , and $776 \mathrm{~cm}^{-1}$, which are assigned to the $\mathrm{Si}-\mathrm{O}$ vibration [4]. In particular, the band near $918 \mathrm{~cm}^{-1}$ indicates the $\mathrm{Si}-\mathrm{OH}$ group and this peak disappears after calcination at $800^{\circ} \mathrm{C}$ (Figure $7(\mathrm{~b})$ ). Bands located between 750 and $1300 \mathrm{~cm}^{-1}$ can be attributed to asymmetric stretching modes of $\mathrm{Si}-\mathrm{O}-\mathrm{Si}$ [13]. There is a broad band around $3300 \mathrm{~cm}^{-1}$ that is representative of an $\mathrm{O}-\mathrm{H}$ vibration. This band results from intra- and inter-molecular hydrogen bonds of the silanol groups $(\mathrm{Si}-\mathrm{OH})$, and residual water and ethanol [4].

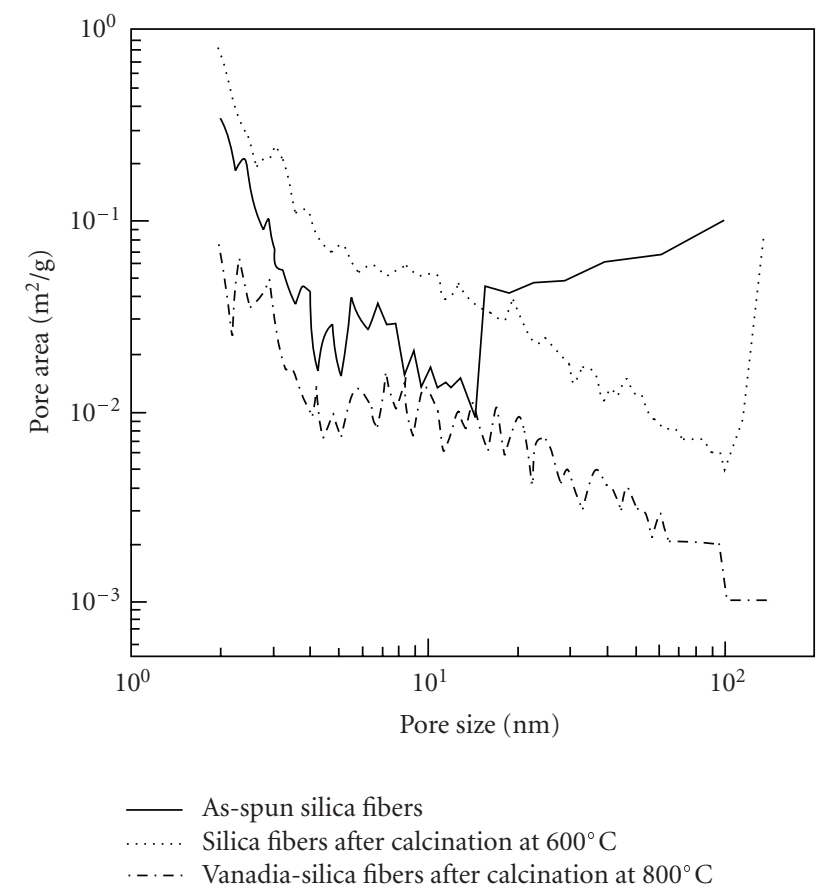

FIGURE 6: Pore area distribution of as-spun silica fibers, silica fibers after calcination at $600^{\circ} \mathrm{C}$ for $2 \mathrm{~h}$, and vanadia/silica fibers after calcination at $800^{\circ} \mathrm{C}$ for $6 \mathrm{~h}$.

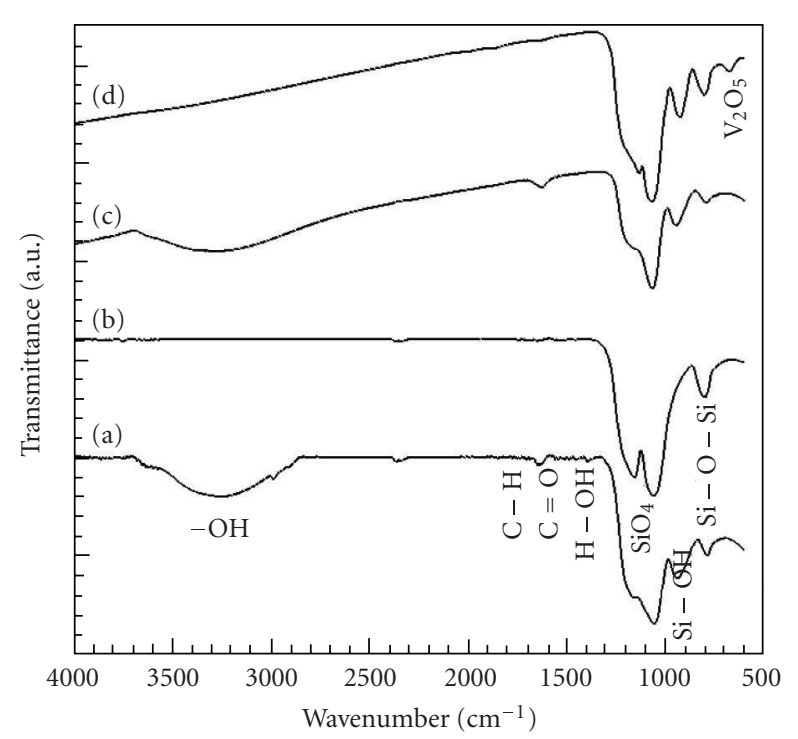

FIGURE 7: FT-IR spectrum of (a) as-spun silica fibers (b) silica fibers after calcination at $800^{\circ} \mathrm{C}$ for $6 \mathrm{~h}$ (c) as-spun $23 \mathrm{~mol} \% \mathrm{~V}$ : Si fibers (d) $23 \mathrm{~mol} \% \mathrm{~V}$ : Si fibers calcined at $800^{\circ} \mathrm{C}$ for $6 \mathrm{~h}$.

After calcination at $800^{\circ} \mathrm{C}$ the broad band peak disappears due to evaporation of water and ethanol from the fibers while peaks are still observed representing $\mathrm{Si}-\mathrm{O}$ vibrations.

FT-IR was conducted on silica fibers containing $23 \mathrm{~mol} \%$ $\mathrm{V}$ : Si before calcination and after calcination at $800^{\circ} \mathrm{C}$, and 


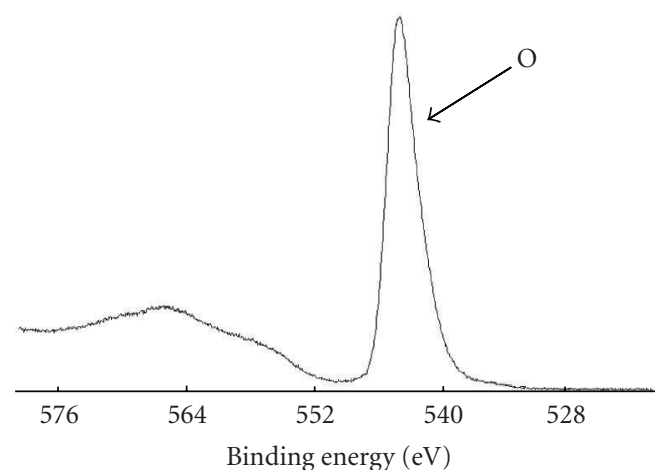

(a)

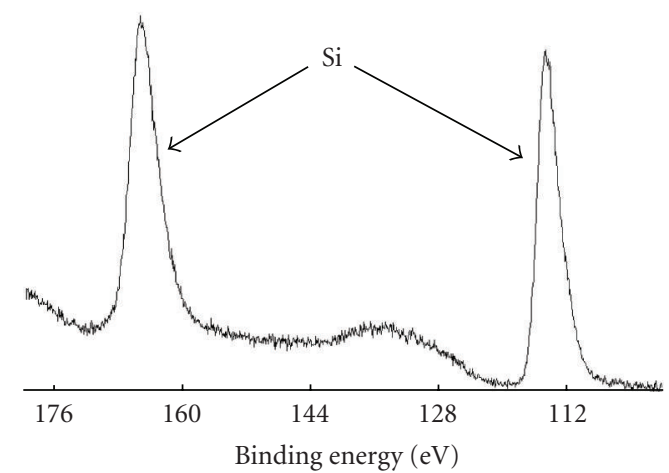

(b)

FIGURE 8: XPS of silica fibers after calcination at $400^{\circ} \mathrm{C}$.

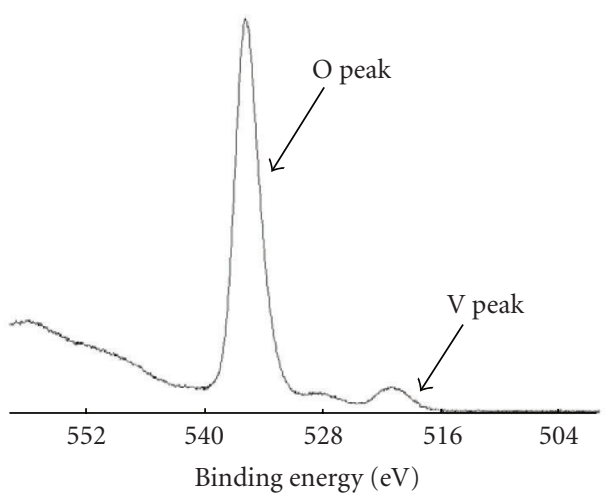

(a)

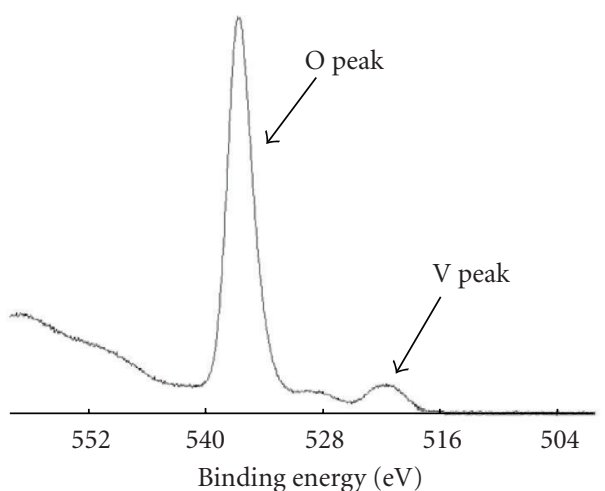

(b)

Figure 9: XPS spectra of (a) as-spun $23 \mathrm{~mol} \% \mathrm{~V}$ : Si fiber (b) $23 \mathrm{~mol} \% \mathrm{~V}$ : Si fiber after calcination at $800^{\circ} \mathrm{C}$ for $6 \mathrm{~h}$.

the spectra are shown in Figures $7(\mathrm{c})$ and $7(\mathrm{~d})$. The spectra for $23 \mathrm{~mol} \% \mathrm{~V}$ : Si fibers before calcination bear a resemblance to those of the silica fibers before calcination (Figure 7(a)) and match. On the other hand, the spectrum for the $23 \mathrm{~mol} \% \mathrm{~V}$ : Si fiber after calcination has one additional peak at $670 \mathrm{~cm}^{-1}$ when compared with the spectrum for the silica fibers after calcination. The band at $670 \mathrm{~cm}^{-1}$ can be attributed to the presence of $\mathrm{V}_{2} \mathrm{O}_{5}$ [14]. The other bands observed may indicate the presence of $\mathrm{V}_{2} \mathrm{O}_{5}$, but they overlap with the $\mathrm{Si}-\mathrm{O}$ vibrations that are also present in the fibers. For example, the $\mathrm{V}=\mathrm{O}$ band is observed around $1000 \mathrm{~cm}^{-1}$ and at $750 \mathrm{~cm}^{-1}$ the $\mathrm{V}-\mathrm{O}-\mathrm{V}$ asymmetric stretch is observed. Bands are observed near these locations for the $23 \mathrm{~mol} \% \mathrm{~V}$ : Si fiber after calcination, but $\mathrm{Si}-\mathrm{O}$ vibrations are also observed at those points as shown in Figure 7(b) [15].

\subsection{Surface characteristics of silica and vanadia/silica nanofibers}

An X-ray photoelectron spectroscopy (XPS) study was carried out on pure silica fibers calcined for $6 \mathrm{~h}$ at $400^{\circ} \mathrm{C}$ and $800^{\circ} \mathrm{C}$. The spectrum, shown in Figure 8, indicates the presence of silicon and oxygen on the surface of fibers. Using (1) the atomic ratio, $N_{\mathrm{A}} / N_{\mathrm{B}}$ of $\mathrm{Si}: \mathrm{O}$ may be found [16],

$$
\frac{N_{\mathrm{A}}}{N_{\mathrm{B}}}=\frac{I_{\mathrm{A}} / S_{\mathrm{A}}}{I_{\mathrm{B}} / S_{\mathrm{B}}}
$$

where $N$ represents the concentration of a relevant element, $i$ (atomic density), and $I_{i}$ and $S_{i}$ are the intensity of the photoelectron signal and atomic sensitivity factor of element, $i$, respectively. $S$ for $\mathrm{O}$ and $\mathrm{Si}$ are 2.494 and 0.903 , respectively [17]. The number of groups was 8 and the number of scans was 20. After calcination at $400^{\circ} \mathrm{C}$ and after calcination at $800^{\circ} \mathrm{C}$ the $\mathrm{Si}: \mathrm{O}$ ratio is around 0.60 , which is within error of 0.5 , the $\mathrm{Si}$ : O ratio to be expected for $\mathrm{SiO}_{2}$.

XPS analysis was also done on silica fibers containing vanadium. As shown in Figure 9 a small vanadium peak is observed for both as-spun fibers and fibers after calcination $[10,18]$. Using (1), where $S$ for vanadium is 5.496 , it was found that the amount of vanadium at the surface of the fibers increased after calcination [16]. The highest V: Si ratio achieved to date using $23 \mathrm{~mol} \% \mathrm{~V}$ : Si fibers is $10 \mathrm{~mol} \%$, which indicates that a little less than one half of the total vanadium reside on the surface of the fiber as $\mathrm{V}_{2} \mathrm{O}_{5}$. 


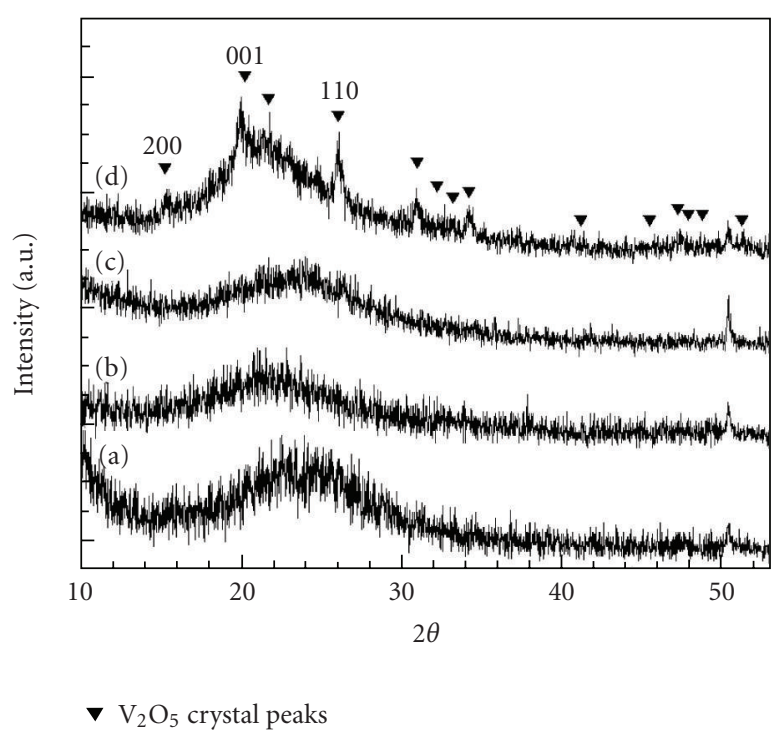

FIGURE 10: XRD patterns of (a) as-spun silica fibers (b) silica fibers calcined at $800^{\circ} \mathrm{C}$ for $6 \mathrm{~h}(\mathrm{c})$ as-spun $23 \mathrm{~mol} \% \mathrm{~V}$ : Si fibers, and (d) $23 \mathrm{~mol} \% \mathrm{~V}$ : Si fibers after calcination at $800^{\circ} \mathrm{C}$ for $6 \mathrm{~h}$.

\subsection{Vanadia crystals in silica nanofibers}

XRD patterns shown in Figures 10(a) and 10(b) for both asspun silica fibers and silica fibers heated at $800^{\circ} \mathrm{C}$ for $6 \mathrm{~h}$ have a broad peak at $2 \theta=23-27^{\circ}$, which represents amorphous $\mathrm{SiO}$ [4]. The silica fibers do not exhibit crystalline characteristics upon calcination at $800^{\circ} \mathrm{C}$.

XRD patterns were obtained for silica fibers containing $23 \mathrm{~mol} \% \mathrm{~V}$ : Si; both as-spun and calcined fibers are shown in Figures 10(c) and 10(d). Before calcination, no $\mathrm{V}_{2} \mathrm{O}_{5}$ crystal peaks are observed. The peaks that are observed after calcination indicate the formation of $\mathrm{V}_{2} \mathrm{O}_{5}$ crystals [6]. Using the Scherrer equation (2) the average crystallite domain size in each direction may be obtained [19],

$$
L_{h k l}=\frac{0.9 \lambda}{B_{h k l} \cos \theta_{0}},
$$

where $B_{h k l}$ is the width at half height, in radians, for a particular $h k l$ reflection, $\lambda$ is the wavelength, and $\theta_{0}$ is the Bragg angle of the reflection. As shown in Table 2, the crystallite domain dimensions are in tens of nanometers, which are similar to the crystalite sizes observed in EFTEM images.

We note that a peak at $2 \theta=50.5^{\circ}$ is observed in each pattern for pure silica fibers and silica fibers containing vanadium which may be attributed to the formation of hydrates and xerogels $[14,20,21]$. This peak only appears when the average diameter of as-spun fibers is below $1 \mu \mathrm{m}$, and thus the surface area of the fibers is possibly large. This peak at $2 \theta=50.5^{\circ}$ decreases after calcination.

A phase diagram obtained from XRD of silica fibers containing various amounts of vanadium is shown in Figure 11. In each case the time of calcination remained the same at $6 \mathrm{~h}$, while the calcination temperature was changed. The lower limit temperature line at a given vanadium concentration

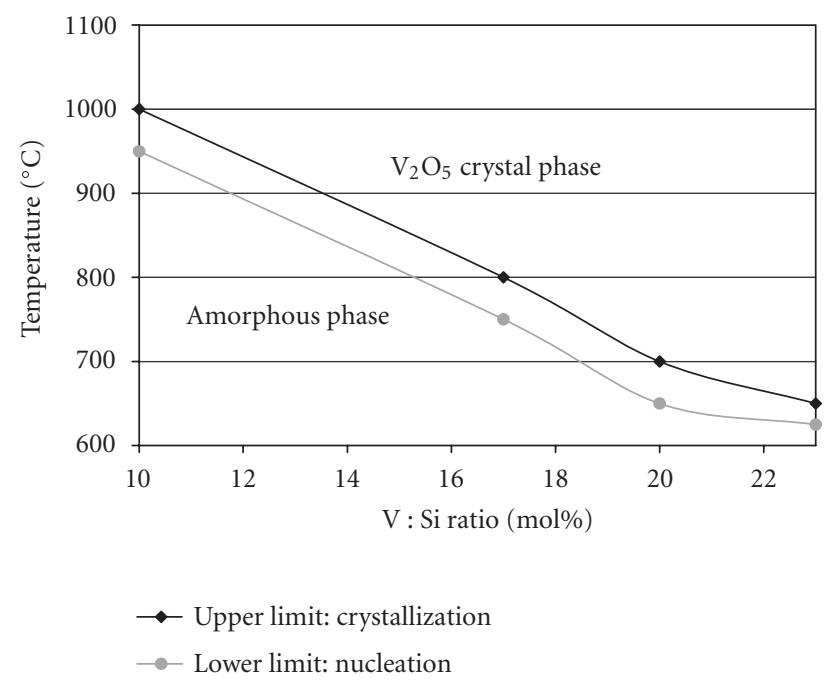

FIGURE 11: Phase diagram for silica fibers containing various concentrations of vanadium oxide.

TABle 2: Average crystallite domain size of $\mathrm{V}_{2} \mathrm{O}_{5}$ on silica nanofibers obtained from XRD patterns and the Scherrer equation.

\begin{tabular}{l|c}
\hline Direction & Average crystallite domain dimension $(\mathrm{nm})$ \\
\hline 200 & 10.1 \\
001 & 13.2 \\
110 & 14.0 \\
\hline
\end{tabular}

represents the first sign of nucleation of $\mathrm{V}_{2} \mathrm{O}_{5}$ crystals, while the upper-limit temperature line represents the onset of the formation of well-defined $\mathrm{V}_{2} \mathrm{O}_{5}$ crystal peaks. Therefore, calcination at or above the lower limit temperature should result in the formation of $\mathrm{V}_{2} \mathrm{O}_{5}$ crystals in the fibers, and the crystal size and degree of crystallization depends on both calcination time and temperature. It is observed that the onset temperature for the phase transition from amorphous to $\mathrm{V}_{2} \mathrm{O}_{5}$ crystals decreases with increasing vanadium content.

The vanadium crystal phases of $23 \mathrm{~mol} \% \mathrm{~V}$ : Si fibers can also be identified with EFTEM images in Figure 12. Although EFTEM only provides the spatial distribution of elements such as $\mathrm{V}$ or $\mathrm{Si}$ (not $\mathrm{V}_{2} \mathrm{O}_{5}$ or $\mathrm{SiO}_{2}$ ) and $\mathrm{O}$ is present in both $\mathrm{V}_{2} \mathrm{O}_{5}$ and $\mathrm{SiO}_{2}$ phases, such elemental mappings can also offer a rough assessment on the size and distribution of $\mathrm{V}_{2} \mathrm{O}_{5}$ crystals in the fibers. Figure 12(b) shows an EFTEM image of a calcined, vanadia/silica fiber where $\mathrm{V}$ was filtered out, and thus distinct bright spots that are tens of nanometers in size correspond to the domains of $\mathrm{V}$ (and thus $\mathrm{V}_{2} \mathrm{O}_{5}$ ) on silica fibers. In Figure 12(c) an EFTEM image of the same fiber after $\mathrm{Si}$ was filtered out, and thus the dark spots represent $\mathrm{V}$ rich regions which are in agreement with bright spots in the V filtered image in Figure 12(b).

\subsection{Higher vanadium content fibers}

Vanadia/silica fibers with a higher vanadium content (50 $\mathrm{mol} \% \mathrm{~V}: \mathrm{Si}$ ) have been electrospun to increase the amount of $\mathrm{V}_{2} \mathrm{O}_{5}$ crystals on the surface and to achieve a higher degree 


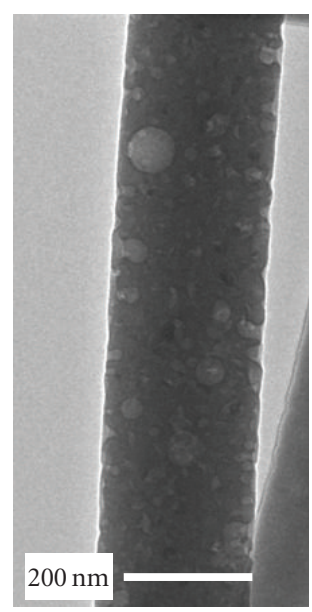

(a)

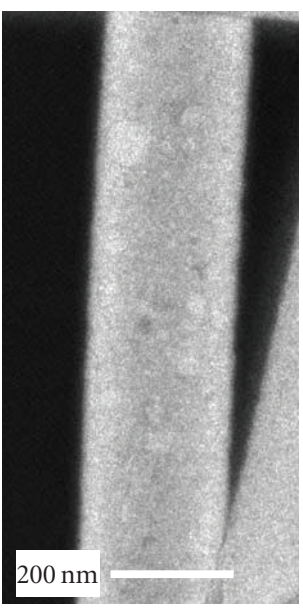

(b)

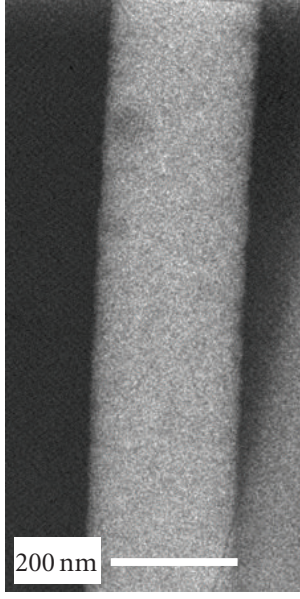

(c)

FIGURE 12: EFTEM images of $23 \mathrm{~mol} \% \mathrm{~V}:$ Si fiber after calcination at $800^{\circ} \mathrm{C}$ (a) with $\mathrm{E}_{\text {filter }}=0 \mathrm{eV}$, (b) with $\mathrm{E}_{\text {filter }}=38 \mathrm{eV}$, (c) with $\mathrm{E}_{\text {filter }}=$ $99 \mathrm{eV}$. Fiber diameter is about $250 \mathrm{~nm}$.

of crystallinity in the fibers. The SEM image in Figure 13(b) shows $50 \mathrm{~mol} \% \mathrm{~V}$ : Si fibers after calcination at $650^{\circ} \mathrm{C}$. A more evident crystal growth on the fiber surface is observed when compared with $23 \mathrm{~mol} \% \mathrm{~V}$ : Si fibers after calcination (Figure $4(\mathrm{~d})$ ) due to the higher vanadium content in the fibers. In addition, the vanadia crystals appear to be aligned along the fiber axis.

XPS was conducted on the $50 \mathrm{~mol} \% \mathrm{~V}$ : Si fibers after calcination at $650^{\circ} \mathrm{C}$. As shown in Figure 14 the amount of vanadium on the surface increased drastically when compared with the $23 \mathrm{~mol} \% \mathrm{~V}: \mathrm{Si}$ fibers, which is consistent with observations made from SEM images. The $\mathrm{V}$ : Si ratio achieved was $27 \mathrm{~mol} \%$, which means that a little more than one half of the vanadium is at or near the fiber surface.

XRD patterns for $50 \mathrm{~mol} \% \mathrm{~V}$ : Si fibers after calcination at $650^{\circ} \mathrm{C}$ and $800^{\circ} \mathrm{C}$ are shown in Figure 15 . The fibers exhibit the growth of $\mathrm{V}_{2} \mathrm{O}_{5}$ crystals and they have a much higher degree of crystallinity than the 23 mol\% V : Si fibers after calcination. From the Scherrer equation it was determined that the average crystal domain size after calcination at $650^{\circ} \mathrm{C}$ and $800^{\circ} \mathrm{C}$ ranges from 31 to $33 \mathrm{~nm}$ and from 17 to $25 \mathrm{~nm}$, respectively. The observed decrease in crystal domain size is most likely due to a possible melting and sublimation of $\mathrm{V}_{2} \mathrm{O}_{5}$ above $690^{\circ} \mathrm{C}$.

\subsection{Hollow vanadia/silica nanofibers via coaxial electrospinning}

Silica fibers containing vanadium have been made using coaxial electrospinning in order to selectively place $\mathrm{V}_{2} \mathrm{O}_{5}$ crystals on the surface of the fibers. Mineral oil and silica precursor containing VOTIP were placed as the core and skin, respectively, and thus hollow silica fibers containing $\mathrm{V}_{2} \mathrm{O}_{5}$ were produced after calcination at high temperature. Calcination at $1000^{\circ} \mathrm{C}$ created some hollow fibers as indicated in

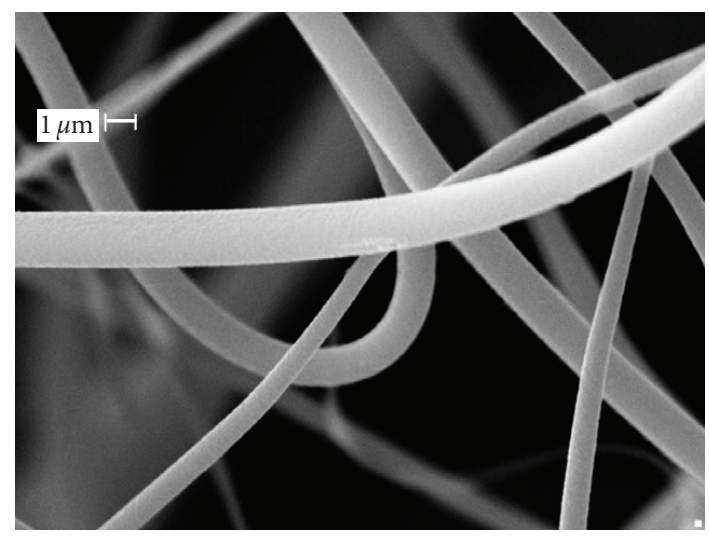

(a)

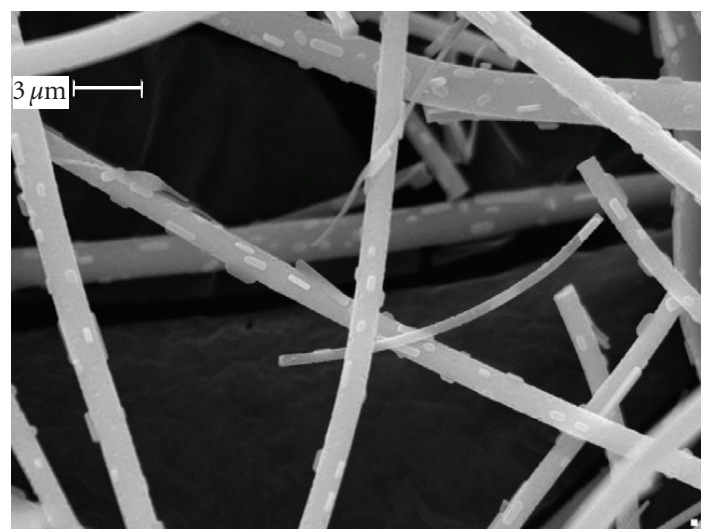

(b)

FIGURE 13: SEM images of (a) as-spun $50 \mathrm{~mol} \% \mathrm{~V}$ : Si fibers, and (b) $50 \mathrm{~mol} \% \mathrm{~V}$ : Si fibers after calcination at $650^{\circ} \mathrm{C}$ for $6 \mathrm{~h}$. 


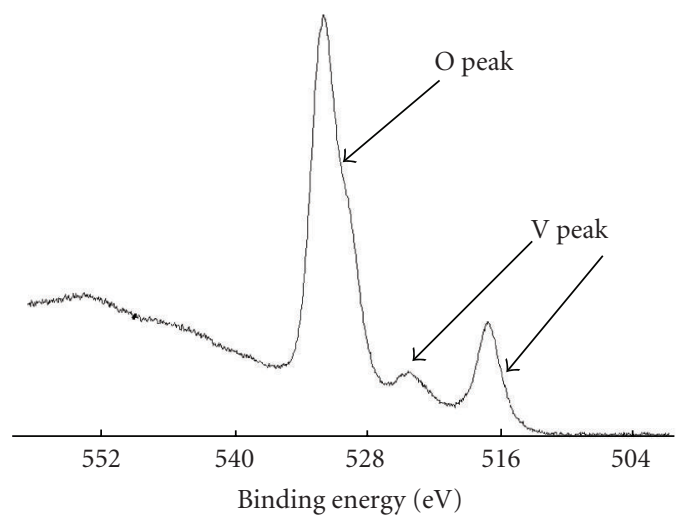

Figure 14: XPS spectrum of $50 \mathrm{~mol} \% \mathrm{~V}$ : Si fibers after calcination at $650^{\circ} \mathrm{C}$ for $6 \mathrm{~h}$.

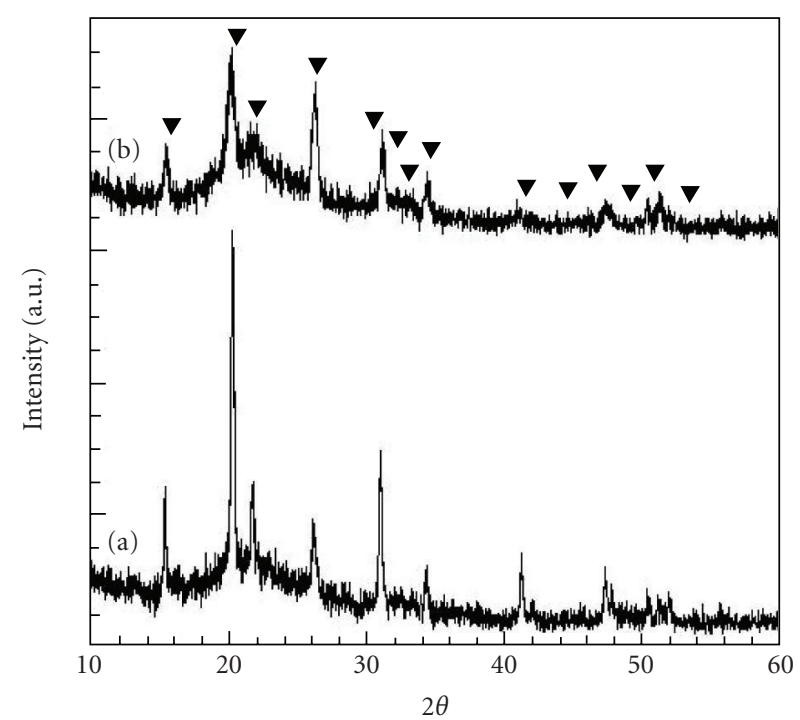

$\nabla \mathrm{V}_{2} \mathrm{O}_{5}$ crystal peaks

FIGURE 15: XRD patterns for (a) $50 \mathrm{~mol} \% \mathrm{~V}$ : Si fibers after calcination at $650^{\circ} \mathrm{C}$ for $6 \mathrm{~h}$, and (b) $50 \mathrm{~mol} \% \mathrm{~V}$ : Si fibers after calcination at $800^{\circ} \mathrm{C}$ for $6 \mathrm{~h}$.

the SEM image shown in Figure 16(a). The inner diameter of the fibers ranges from about $500 \mathrm{~nm}$ to $1 \mu \mathrm{m}$ and the thickness of the core shell is about $300 \mathrm{~nm}$. Hollow fibers are advantageous because the coaxial scheme can greatly reduce the loading required of metal oxides by placing the metal oxide particles exclusively in the skin layer.

TEM images of two fibers cut open in Figure 16(b) also show the hollow nature of the fibers after calcination at $1000^{\circ} \mathrm{C}$. The images demonstrate the domains of crystals (bright spots) on the surface of both the inner and outer side of the fiber, which suggests that hollow fibers can possibly increase the number of active sites of the fiber, when compared with monoaxial fibers.

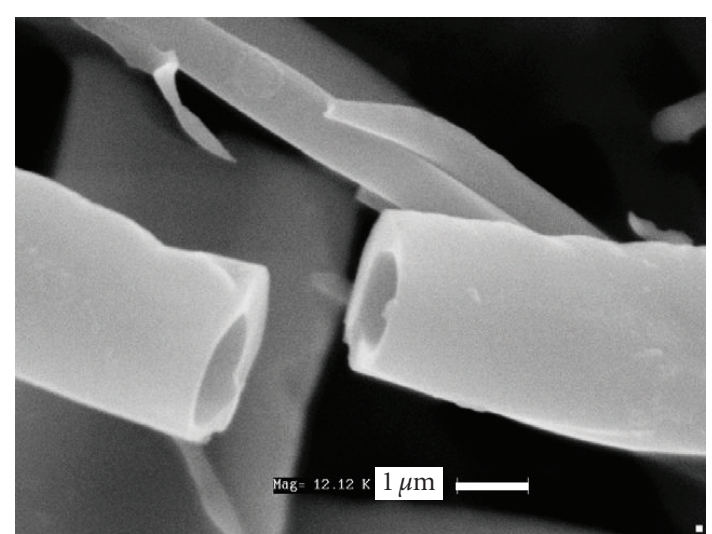

(a)

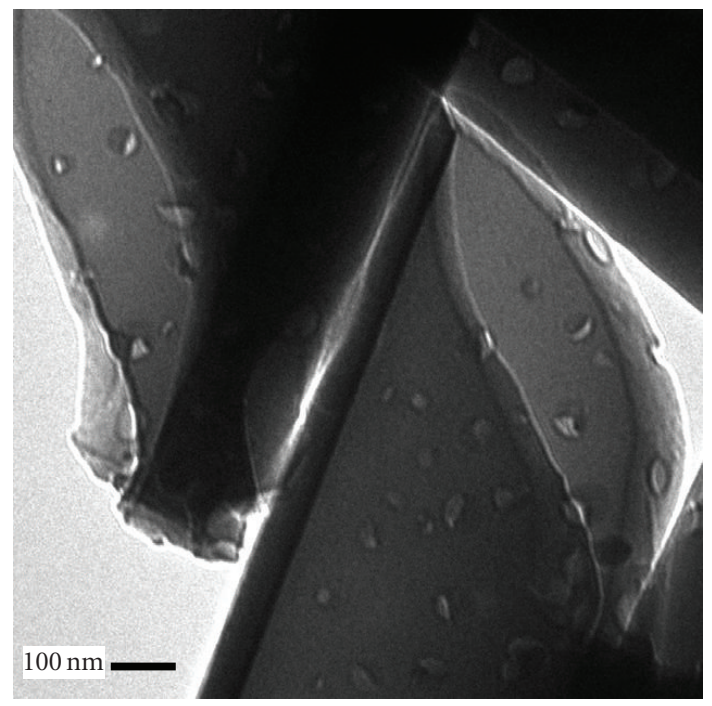

(b)

FIGURE 16: Coaxially spun silica fibers containing $23 \mathrm{~mol} \% \mathrm{~V}$ : Si after calcination at $1000^{\circ} \mathrm{C}$ for $6 \mathrm{~h}$ (a) SEM image and (b) TEM image.

\section{CONCLUSION}

Silica nanofiber mats have been produced by combining solgel synthesis and electrospinning without using any polymer binder. SEM images show silica fibers range in diameter from 100 to $400 \mathrm{~nm}$ and the morphology of the silica fibers was preserved after calcination at $600^{\circ} \mathrm{C}$. TGA showed an overall weight loss of $17 \mathrm{wt} \%$ at $800^{\circ} \mathrm{C}$. The BET surface area of the fibers increased dramatically after calcination at $600^{\circ} \mathrm{C}$, while the fibers contain a very large number of micropores. FTIR showed $\mathrm{Si}-\mathrm{O}$ vibrations and the removal of residual solvents after calcination. XPS data after calcination indicated the presence of the correct ratio of Si to O. XRD showed the fibers remained amorphous after calcination and TEM indicates a change in morphology and the collapse of pores in the fibers after calcination at $800^{\circ} \mathrm{C}$. 
This new scheme to produce inorganic nanofibers has been extended to the development of silica nanofiber mats containing vanadium pentoxide crystals by directly incorporating the vanadium oxide precursor into a sol-gel synthesis reaction. SEM images showed vanadia/silica fibers are also submicron in diameter. TGA demonstrated the composition of the fibers continued to change up to $900^{\circ} \mathrm{C}$. FT-IR data confirms the formation of $\mathrm{V}_{2} \mathrm{O}_{5}$ after calcination at $800^{\circ} \mathrm{C}$. XPS analysis showed an increase in vanadium contents at the fiber surface after calcination. XRD indicates $\mathrm{V}_{2} \mathrm{O}_{5}$ crystals form after calcination and the crystal sizes match those observed from TEM. EFTEM images demonstrate vanadia crystal growth on the surface of the fibers. SEM images of high vanadium content $(50 \mathrm{~mol} \% \mathrm{~V}: \mathrm{Si})$ fibers show more crystal growth on the fiber surface and the crystals are mostly aligned along the fiber axis. XPS shows an increase in vanadium contents at the fiber surface, while XRD shows an increase in the degree of crystallinity when compared with $23 \mathrm{~mol} \% \mathrm{~V}$ : Si fibers. Hollow silica fibers containing vanadium oxide crystals on the surface have also been produced using coaxial electrospinning in order to selectively place $\mathrm{V}_{2} \mathrm{O}_{5}$ at the surface of the fiber.

\section{ACKNOWLEDGMENTS}

This work was supported by the United States Department of Agriculture through a National Research Initiative Competitive Grant in a Nanoscale Science and Engineering, Award no. 2005-35603-15298. The authors also thank Christina Jackson for her help in developing silica fibers with high vanadia content.

\section{REFERENCES}

[1] H. Fong and D. H. Reneker, "Electrospinning and the formation of nanofibers," in Structure Formation in Polymeric Fibers, D. R. Salem, Ed., chapter 6, Hanser Gardner, Cincinnati, Ohio, USA, 2001.

[2] Y. Dzenis, "Spinning continuous fibers for nanotechnology," Science, vol. 304, no. 5679, pp. 1917-1919, 2004.

[3] D. Li and Y. Xia, "Electrospinning of nanofibers: reinventing the wheel?" Advanced Materials, vol. 16, no. 14, pp. 1151-1170, 2004.

[4] S.-S. Choi, S. G. Lee, S. S. Im, S. H. Kim, and Y. L. Joo, "Silica nanofibers from electrospinning/sol-gel process," Journal of Materials Science Letters, vol. 22, no. 12, pp. 891-893, 2003.

[5] Z.-M. Huang, Y.-Z. Zhang, M. Kotaki, and S. Ramakrishna, "A review on polymer nanofibers by electrospinning and their applications in nanocomposites," Composites Science and Technology, vol. 63, no. 15, pp. 2223-2253, 2003.

[6] P. Viswanathamurthi, N. Bhattarai, H. Y. Kim, and D. R. Lee, "Vanadium pentoxide nanofibers by electrospinning," Scripta Materialia, vol. 49, no. 6, pp. 577-581, 2003.

[7] L. C. Klein, "Part III. Continuous, discontinuous, and woven fibers," in Sol-Gel Technology for Thin Films, Fibers, Preforms, Electronics, and Specialty Shapes, Knovel, Binghamton, NY, USA, 1988.

[8] D. D. Beck and R. W. Siegel, "Dissociative adsorption of hydrogen sulfide over nanophase titanium dioxide," Journal of Materials Research, vol. 7, no. 10, pp. 2840-2845, 1992.
[9] M. C. Carotta, M. Ferroni, S. Gherardi, et al., "Thick-film gas sensors based on vanadium-titanium oxide powders prepared by sol-gel synthesis," Journal of the European Ceramic Society, vol. 24, no. 6, pp. 1409-1413, 2004.

[10] S. Zhuiykov, W. Wlodarski, and Y. Li, "Nanocrystalline $\mathrm{V}_{2} \mathrm{O}_{5}$ $\mathrm{TiO}_{2}$ thin-films for oxygen sensing prepared by sol-gel process," Sensors and Actuators B: Chemical, vol. 77, no. 1-2, pp. 484-490, 2001.

[11] D. Li and Y. Xia, "Direct fabrication of composite and ceramic hollow nanofibers by electrospinning," Nano Letters, vol. 4, no. 5, pp. 933-938, 2004.

[12] S.-H. Tan, R. Inai, M. Kotaki, and S. Ramakrishna, "Systematic parameter study for ultra-fine fiber fabrication via electrospinning process," Polymer, vol. 46, no. 16, pp. 6128-6134, 2005.

[13] Q. Hu, H. Suzuki, H. Gao, H. Araki, W. Yang, and T. Noda, "High-frequency FTIR absorption of $\mathrm{SiO}_{2} / \mathrm{Si}$ nanowires," Chemical Physics Letters, vol. 378, no. 3-4, pp. 299-304, 2003.

[14] M. Gotić, S. Popović, M. Ivanda, and S. Musić, "Sol-gel synthesis and characterization of $\mathrm{V}_{2} \mathrm{O}_{5}$ powders," Materials Letters, vol. 57, no. 21, pp. 3186-3192, 2003.

[15] G. P. Holland, F. Huquenin, R. M. Torresi, and D. Buttry, "Comparison of $\mathrm{V}_{2} \mathrm{O}_{5}$ xerogels prepared by the vandate and alkoxide routes using X-ray absorption and other methods," Journal of the Electrochemical Society, vol. 150, no. 6, pp. A721A725, 2003.

[16] I. Losito, L. Sabbatini, and J. A. Gardella Jr., "Electron, ion, and mass spectroscopy," in Comprehensive Desk Reference of Polymer Characterization and Analysis, R. F. Brady Jr., Ed., Oxford University Press, New York, NY, USA, 2003.

[17] C. D. Wagner, et al., "Appendix 6," in Practical Surface Analysis. Vol. 1, John Wiley \& Sons, New York, NY, USA, 2nd edition, 1990.

[18] A. Lavacchi, B. Cortigiani, G. Rovida, U. Bardi, and A. Atrei, "Composition and structure of tin/vanadium oxide surfaces for chemical sensing applications," Sensors and Actuators B: Chemical, vol. 71, no. 1-2, pp. 123-126, 2000.

[19] J. Blackwell, "Microstructure characterization," in Structure Formation in Polymeric Fibers, D. R. Salem, Ed., chapter 13, Hanser Gardner, Cincinnati, Ohio, USA, 2001.

[20] O. Durupthy, N. Steunou, T. Coradin, J. Maquet, C. Bonhomme, and J. Livage, "Influence of $\mathrm{pH}$ and ionic strength on vanvdium(v) oxides formation. From $\mathrm{V}_{2} \mathrm{O}_{5} . n \mathrm{H}_{2} \mathrm{O}$ gels to crystalline $\mathrm{NaV}_{2} \mathrm{O}_{8} \cdot 1.5 \mathrm{H}_{2} \mathrm{O}$," Journal of Materials Chemistry, vol. 15, no. 10, pp. 1090-1098, 2005.

[21] M. J. Niederberger, "Synthesis and characterization of novel micro- and nanostructured vanadium, molybdenum, and iron oxides," Dissertation, Swiss Federal Institute of Technology, Lausanne, Switzerland, 2000. 

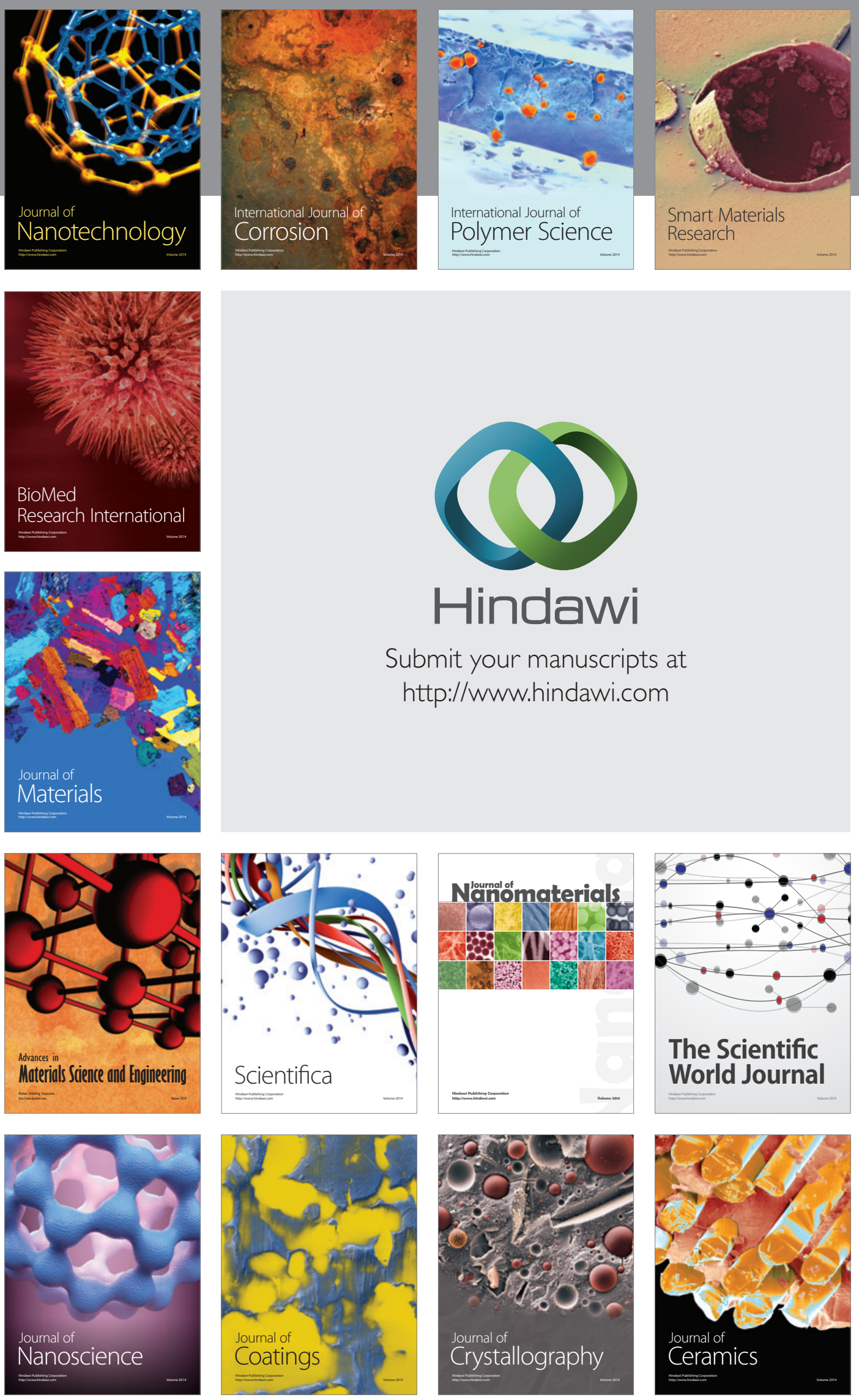

The Scientific World Journal

Submit your manuscripts at

http://www.hindawi.com

\section{World Journal}

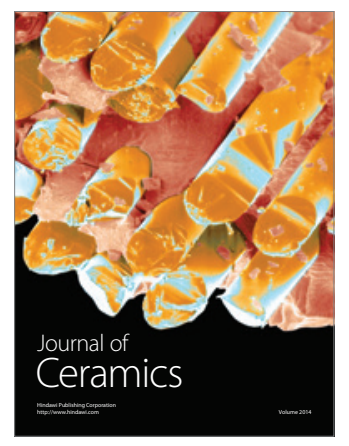

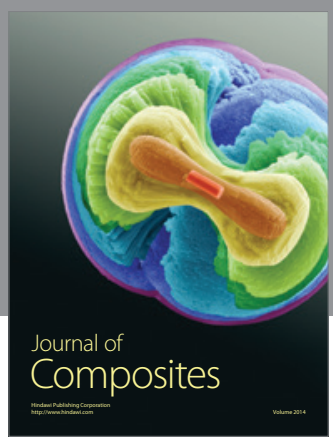
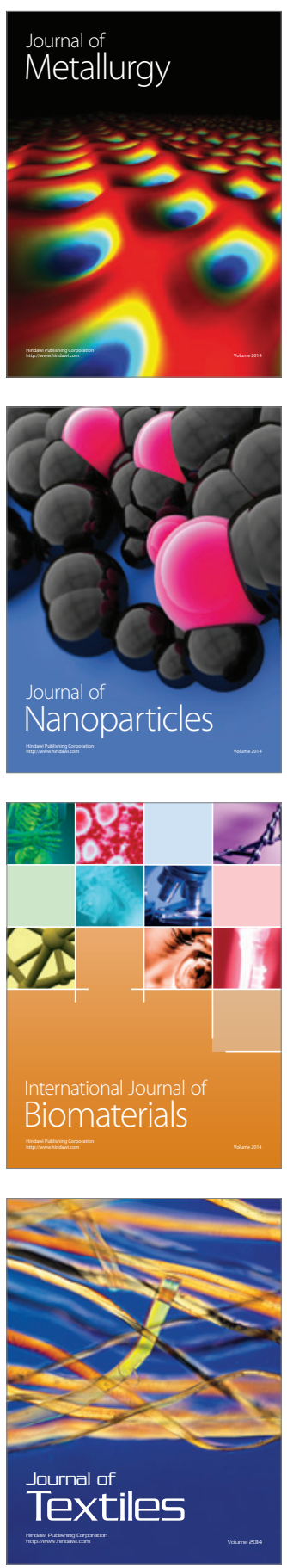